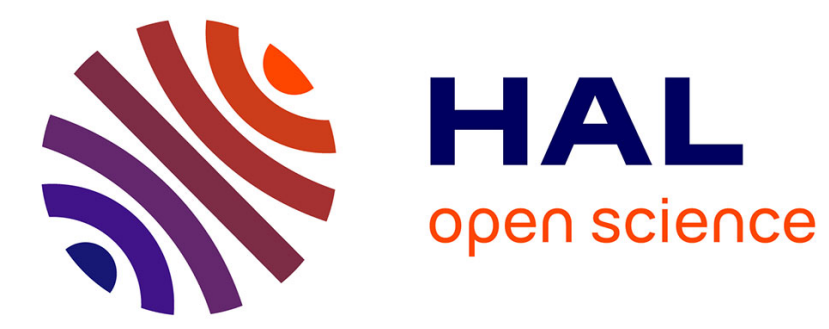

\title{
Insights into function and evolution of parasitoid wasp venoms
}

\author{
Marylène Poirie, Dominique Colinet, Jean-Luc Gatti
}

\section{To cite this version:}

Marylène Poirie, Dominique Colinet, Jean-Luc Gatti. Insights into function and evolution of parasitoid wasp venoms. Current Opinion in Insect Science, 2014, 6, pp.52-60. 10.1016/j.cois.2014.10.004 . hal02634195

\section{HAL Id: hal-02634195 \\ https://hal.inrae.fr/hal-02634195}

Submitted on 27 May 2020

HAL is a multi-disciplinary open access archive for the deposit and dissemination of scientific research documents, whether they are published or not. The documents may come from teaching and research institutions in France or abroad, or from public or private research centers.
L'archive ouverte pluridisciplinaire HAL, est destinée au dépôt et à la diffusion de documents scientifiques de niveau recherche, publiés ou non, émanant des établissements d'enseignement et de recherche français ou étrangers, des laboratoires publics ou privés. 


\author{
Poirié Marylène ${ }^{1,2,3}$, Colinet Dominique ${ }^{1,2,3}$ and \\ Gatti Jean-Luc 1,2,3
}

\begin{abstract}
Most species in the order Hymenoptera are parasitoids that lay eggs and develop in or on the body of arthropod hosts. Several factors contribute to successful parasitism including venoms that wasps inject into hosts when ovipositing. Here, we review the composition, function and diversity of parasitoid venoms with emphasis on studies of wasps that parasitize hosts in the genus Drosophila. The comparative literature indicates that some closely related species parasitizing the same host do not share any abundant venom protein while unrelated species sometimes have the same major venom component. Within species, studies also identify intraspecific variation that suggests parasitoid venoms may rapidly evolve. Overall, however, our picture of venom function remains largely unclear and will require additional comparative data on the composition of venoms from a greater diversity of species than exists currently. Further advances will come mainly from experimental data using functional tools, such as RNA interference.
\end{abstract}

\begin{abstract}
Addresses
${ }^{1}$ Institut National de la Recherche Agronomique (INRA), Evolution and Specificity of Multitrophic Interactions (ESIM), UMR 1355 Institut Sophia Agrobiotech (ISA), Sophia Antipolis, France

${ }^{2}$ Centre National de la Recherche Scientifique (CNRS), UMR 7254 Sophia Antipolis, France

${ }^{3}$ Université Nice Sophia Antipolis, UFR Sciences, Sophia Antipolis, France
\end{abstract}

Corresponding author: Marylène, Poirié (poirie@sophia.inra.fr)

Current Opinion in Insect Science 2014, 2:xx-yy

This review comes from a themed issue on Parasites/parasitoids/ biological control

Edited by Michael R Strand

doi:10.1016/j.cois.2014.10.004

2214-5745/Published by Elsevier Inc.

\section{Introduction}

Venomous organisms are found in all major animal phyla and occupy virtually all habitats on Earth $\left[1^{\circ}\right]$. Venoms have also convergently evolved to perform two key functions: subdue prey or hosts and/or provide defense against potential predators. Key areas of interest in the study of venoms include the characterization of the molecules in venom secretions, studying the function of particular venom components, and analyzing venom diversity among species, populations or individuals [2,3]. In this review, we discuss key features of the venoms produced by parasitoid wasps with emphasis on endoparasitic species that parasitize larval stage Drosophila sp.

All female hymenopterans produce venoms in a venom gland that is part of the reproductive tract (Figure 1). Venoms from bees, ants and other aculeates have a variety of functions, whereas venoms that parasitoid wasp females inject into hosts when laying eggs are often required for parasitism success. Parasitoid larvae develop on (ectoparasitoids) or in (endoparasitoids) a given arthropod host by consuming tissues. The hosts of parasitoids usually die after wasp offspring complete their development [4]. Parasitoids thus often play important ecological roles in controlling host populations, and are also widely used as biological control agents to manage economically important pest species. Endoparasitoids commonly induce a host immune response, called encapsulation, which results in layers of hemocytes surrounding the wasp egg or larva. Capsules also often melanize due to activation of the prophenoloxidase (PO) cascade, as shown for species that parasitize Drosophila larvae [5]. However, endoparasitoids have evolved different strategies to evade being encapsulated in permissive hosts. Theses include the injection of venoms into hosts, which contain immune suppressive molecules $\left[6,7^{\circ}\right]$. Parasitoid venoms also have other functions that include the alteration of host behavior (e.g. immobilization, foraging), metabolism, development and reproduction [4].

\section{A diversity of venom proteins have been identified from different parasitoid species}

Comparative studies from different animals indicate that venoms are usually complex mixtures of proteins and non-proteinaceous compounds whose production can be metabolically costly $\left[1^{\circ}\right]$. Studies conducted in select species further suggest that individual venom components can also have a high degree of functional redundancy $\left[1^{\circ}\right]$. Thus, studies comparing venoms between different families and species (diversity) as well as between different individuals of the same population (variability) are often highly challenging and require the use of multiple approaches.

In the case of parasitoid wasps, venoms have thus far been analyzed in 17 species belonging to 5 different families, 
using different approaches $\left[7^{\bullet}, 8^{\bullet}, 9,10,11^{\bullet}, 12^{\bullet}, 13-17\right]$. Only the most recent of these studies combine transcriptomics of venom glands and proteomics to identify the proteins in the venom that wasps inject into hosts. Among the diversity of proteins that have been identified in parasitoid venoms, more than 60 share significant homology with proteins which have known functions (Table 1). However, no predicted function nor experimental data exist for the vast majority of parasitoid venom proteins so their specific roles in parasitism largely remain unknown. The absence of experimental data also holds for the venoms produced by most other animals $\left[1^{\circ}, 18^{\circ}\right]$ resulting in venoms being functional black boxes'.

Current understanding of parasitoid venom composition and function is also strongly biased. Indeed, most available data focus on proteins that are highly abundant or are structurally related to genes in databases with predicted functions. Some of these factors, including serine proteases, metalloproteases or esterases are shared between many wasp species while others are known from only one or a small number of species (Table 1). Yet some enzymes, such as oxidoreductases, function in hosts at very low concentrations, which indicates that focusing solely on abundant components in venom can potentially lead to overlooking factors that also have important functions in parasitism.

A related challenge is how to compare the venom proteins produced by species in different taxa. Taxon sampling and knowledge on identified proteins at present are too shallow to assess whether venom composition in a given parasitoid species is most influenced by wasp phylogeny, the taxon of the host (e.g. Diptera, Lepidoptera, Homoptera), the host range of the wasp being studied (specialist versus generalist) or details regarding how the parasitoid interacts with host physiology (e.g. immunoevasion or immunosuppression, or use of venom alone versus use of venom in combination with symbiotic viruses).

\section{Variation in venom composition also exists between closely related species or strains: the example of Leptopilina wasps}

Recent work on wasps from the genus Leptopilina (Figitidae) reveals that venom composition can mainly differ between closely-related species that parasitize the same host, yet the most abundant venom protein in a given species can be quite similar to those in a more phylogenetically distant species $\left[11^{\circ}, 12^{\circ}\right]$. Comparison of venom proteins between strains of Leptopilina boulardi also identifies many quantitative differences $\left[12^{\circ}\right]$. The variation in cis-regulation of one of these venom genes ( $L b G A P)$ was previously suggested to explain the variation that exists in L. boulardi virulence [19]. Altogether, these findings suggest the abundance of certain venom components in $L$. boulardi rapidly evolve through changes in gene expression levels. The presence or abundance of some venom proteins may thus reflect short-term adaptations rather than phylogenetic relationships. Understanding of the molecular mechanisms underlying changes in venom gene expression (e.g. cis-regulation, epigenetic regulation) is currently an important challenge.

Inter-individual variation in parasitoid venoms Little is known about the variability of parasitoid venom at the individual level. However, we recently used a method based on one-dimensional SDS-PAGE analysis $(<10$ to $>200 \mathrm{kDa}$ range) [20] to compare venom protein profiles between individual wasps of the same species. This yielded the first evidence of inter-individual variation of venom in laboratory strains and natural populations of Leptopilina and Psyttalia (Braconidae) wasps [13]. Figure 1 illustrates these differences in the case of Leptopilina sp.

Digital imaging techniques and the use of $\mathrm{R}$ functions further allow semi-automated analysis and comparison of individual protein profiles from large samples (MathéHubert et al., unpublished). This enables several new questions to be addressed including whether venom composition varies within and between populations of the same wasp species, and whether venom composition responds to selection associated with host resistance or availability and which are the proteins that evolve. Parasitoids can indeed adapt to a variety of hosts, each of which being most efficiently subdued with a different venom formulation. Venom of generalist species may thus either contain factors efficient against multiple hosts, or 'cocktails' of virulence factors active against different hosts. In this last case, variation of venom composition may occur depending of the hosts availability. Finally, venom profiles could be used as 'quality control' markers to assess whether the appropriate strain of a given species is used for efficient biological control of a given pest.

Venom gland proteins with roles in secretion

Like other secretory organs, venom glands rely on a cellular secretome to secrete the proteins present in venom. Core proteins associated with the cellular secretome may have several functions including regulation of the secretion process itself (e.g. folding, quality control), post-secretory protein modifications (e.g. proteolysis, sugar modifications) and stabilization of venom components (e.g. inhibition of protease activity, antioxidant activity). Molecular chaperones, such as endoplasmin or heat shock protein 70 , have also been proposed to be involved in the secretion and stabilization of venom proteins [10,21]. An extracellular superoxide dismutase, identified in low abundance in venom may also protect stored venom proteins from oxidation rather than act as a virulence factor [22]. 
Table 1

State of the art synthesis of the venom proteins identified from parasitoid wasps, having known or putative biochemical functions.

Venom proteins Demonstrated effect on the

host physiology

Species

\section{Enzymes}

Alpha-N-acetyl

glucosaminidase

glucosaminidase
Alkaline phosphatase

Aminotransferase-like

venom protein

Angiotensin-converting

enzyme

Apyrase

Arginine kinase

Arylsulfatase

Aspartylglucosaminidase

ATP synthase

C1A protease

Chitinase

Dipeptidylpeptidase IV

Endonuclease-like

venom protein

Esterase/lipase

Gamma glutamyl

transpeptidase

Induction of apoptosis in

Glucose-methanol-

choline (GMC)

oxidoreductase

Glycosyl hydrolase

Inosine-uridine preferring

nucleoside hydrolase

Laccase

Metalloprotease

Toxicity toward the host,

manipulation of host

Multiple inositol

development (Ep) [46]

polyphosphate

phosphatase-like venom

protein

Phenoloxidase

Phospholipase B

Polynucleotide

kinase/phosphatase

Sarco/endoplasmic

reticulum calcium

ATPase

Serine proteases and

serine protease

homologs

host ovaries (Ae) [27]

Ae [10] At Co

G1 [17]

Hd [9]

b [11 $\left.{ }^{\circ}\right]\left[12^{\circ}\right]$

$\operatorname{Lh}\left[11^{\circ}\right]\left[12^{\circ}\right] \quad \mathrm{Ma}$

Md [16]

Nv Ph

$P p \quad P$

calcium levels and inhibition

of cellular immunity (GI) [17]

Inhibition of melanization (Cr)

[23]

Comment citer ce document :

Poirie, M. (Auteur de correspondance), Colinet, D., Gatti, J.-L. (2014). Insights into function

and evolution of parasitoid wasp venoms. Current Opinion in Insect Science. DOI

10.1016/j.cois.2014.10.004 
Table 1 (Continued)

Venom proteins

Superoxide dismutase

Trehalase

Tyrosine 3/tryptophan

5-monooxygenase

Venom acid

phosphatase

Recognition/binding proteins

Beta-1,3-glucan

recognition protein

Chitin binding protein

Fibronectin

domain-containing

protein

Lectin

Low-density lipoprotein

receptor

Sushi/SCR/CCP

domain-containing protein

Protease inhibitors

Cysteine-rich protease

inhibitor

Kazal-type serine

protease inhibitor

Serpin

Tissue inhibitor of

metalloproteinase

Immune related proteins

Calreticulin

Inhibition of melanization (Lb) +

[24]

In vitro inhibition of

Drosophila phenoloxidase

activity (Lb) [22]

C1q-like venom protein

Complement-binding

protein

Immunoglobulin-like

venom protein

Chaperone

Endoplasmin

Heat shock protein

Cytoskeleton components

Actin

Tropomyosin
Inhibition of hemocyte

spreading behavior

suppression of

encapsulation (Cr) [47]
Species

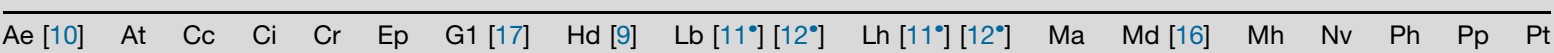

Comment citer ce document:

Poirie, M. (Auteur de correspondance), Colinet, D., Gatti, J.-L. (2014). Insights into function

and evolution of parasitoid wasp venoms. Current Opinion in Insect Science. DOI

10.1016/j.cois.2014.10.004 
Table 1 (Continued)

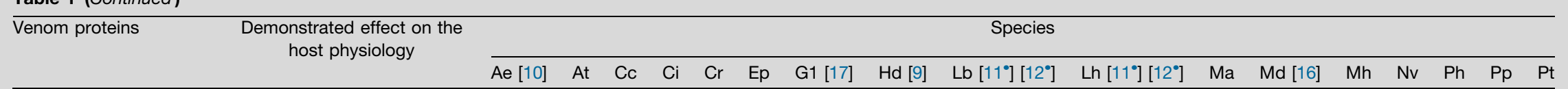

\section{Neurotoxin-like/Paralytic factors}

Pimplin Host paralysis [48]

Vn4.6 (similar to Inhibition of melanization (Cr)

atracotoxins) [49]

\section{Others}

Chemosensory

protein-like protein

Cystein-rich proteins

Elongation factors

General odorant binding

protein

Hexamerin

Imaginal disk growth

factors-like

Insect hemocyte

anti-aggregation

protein

Inhibition of hemocyte

spreading and aggregation,

suppression of

Leucine-rich repeat

domain-containing

protein

Plancitoxin

RhoGAP

encapsulation $(\mathrm{Ph})[50]$

Changes in host lamellocyte

morphology, suppression of

encapsulation (Lb) [51]

Similar to lethal (1) G0193

isoforms

Yellow-e3-like protein

This table has been updated and modified from Table 1 in [ $\left.8^{\circ}\right]$. Please refer to this paper for most of the references. Data obtained since publication of [ $\left.8^{\circ}\right]$ are quoted in the table and in the reference list. Ae, Aphidius ervi. At, Asobara tabida. Cc, Chelonus sp. near curvimaculatus. Ci, Chelonus inanitus. Cr, Cotesia rubecula. Ep, Eulophus pennicornis. G1, Ganaspis sp. 1. Hd, Hyposoter didymator. Lb, Leptopilina boulardi. Lh, Leptopilina heterotoma. Ma, Microctonus aethiopoides. Md, Microplitis demolitor. Mh, Microctonus hyperodae. Nv, Nasonia vitripennis. Ph, Pimpla didymator. Lb, Leptopilina boulardi. Lh, Leptopilina heterotoma.
hypochondriaca. Pp, Pteromalus puparum. Pt, Pimpla turionellae. 
Figure 1

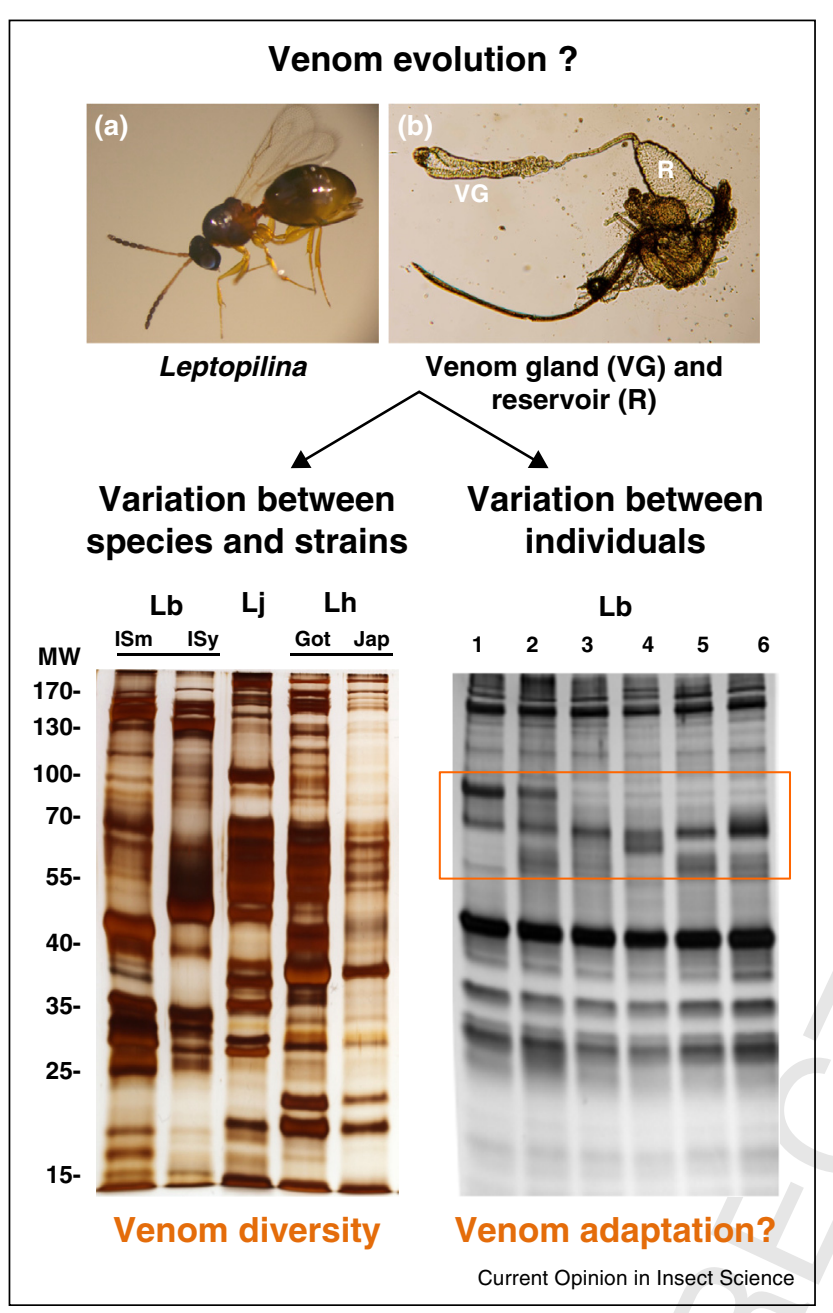

Diversity and variability of venom protein composition in Leptopilina $\mathrm{sp}$.

The upper part of the figure shows an adult female wasp (A) and a venom apparatus (B) which consists of secretory venom gland cells (VG) and venom gland reservoir (R) where venom is stored. The lower part of the figure shows venom proteins that have been separated on a $12 \%$ SDS-PAGE and silver stained. The left gel compares two strains of $L$. boulardi (ISm and ISy, respectively from Nasrallah, Tunisia and Brazzaville, Congo), two strains of $L$. heterotoma (Got, from Gotheron, France and Jap, from Japan), and one strain of $L$. japonica. Clear differences are seen between species and between strains, especially in $L$. boulardi. Molecular mass markers (MW) are indicated to the left of the gel in kilodaltons. The right gel shows inter-individual variability in $L$. boulardi venom profiles through comparison of six individuals from a population recently collected in the South of France. Note the variation among individuals as highlighted by the orange box.

Thus, some of these core factors are present in venom although they may have no functions when injected into hosts, whereas others have potentially evolved functions in parasitism. For instance, some of the proteases and serine protease inhibitors (serpins) identified in parasitoid venom act as inhibitors of the PO cascade, thus altering the host immune response [23,24], while others might be involved in post-secretory modifications or protection of venom proteins. Another example is aspartylglucosaminidase (AGA), a lysosomal asparaginase, abundant in L. heterotoma and Asobara tabida venom $\left[11^{\bullet}, 12^{\bullet}, 25\right]$, which plays a role in glycoproteins degradation by cleaving the bonds between an asparagine and an N-acetylglucosamine. AGA may thus have a role in post-secretory modifications of venom proteins. Yet asparaginase is used in leukemia treatment to hydrolyze circulating asparagine (ASN), leading to its continuous depletion and the death of leukemic blast cells that are unable to produce ASN [26]. Similarly, parasitoid AGA might modulate host ASN and thus affect cells requiring high levels of extracellular ASN. Putative targeted effects through amino acid metabolism are also illustrated by the case of a gamma glutamyl transferase (AeGGT), a major protein in the venom of the braconid wasp Aphidius ervi $[10,27]$. GGTs are generally membrane-anchored enzymes that regulate intracellular levels of glutathione, which functions as a cellular antioxidant [28]. Injection of the soluble AeGGT into aphids strongly reduces fertility through degeneration of ovaries [27] possibly because AeGGT reduces antioxidant levels which lead to apoptosis of ovarian cells.

\section{The origin and evolution of parasitoid venom proteins}

Venom proteins share several characteristics such as specific and/or high abundance in venom tissues and secretion in venom $\left[1^{\bullet}, 29,30\right]$. Many proteins in venom also arise from duplication of genes with other functions in the wasp $\left[1^{\bullet}, 29,30\right]$. A striking example is the major venom protein LbGAP of $L$. boulardi, which only consists of a signal peptide required for secretion and a RhoGAP domain, derived from this of the wasp cellular RhoGAP, that interacts in vitro with Rac1 and Rac2 from D. melanogaster [31]. Different models, such as the PSR model (Protein Subcellular Relocalization) [32] may explain the acquisition of a signal peptide by LbGAP that allows it to be secreted in the venom gland. Proteomic analysis indicates that $L$. boulardi venom contains several other RhoGAPs that arose from further duplications of LbGAP but all contain mutations in key residues for interaction with RacGTPases and/or catalytic activity $\left[12^{\circ}\right.$ ]. Similar duplication events followed by functional modifications were also recently described for the gamma glutamyl transferase protein present in the venom of A. ervi [10]. Finally, the importance of duplication as a key process in venom evolution was highlighted by the identification of gene families expressed in Microplitis demolitor venom glands, including reprolysin metalloprotease-like genes [16]. The recurrent occurrence of divergent proteins of the same family in venom suggests accelerated Darwinian evolution. Although similar in structure, some of these proteins may have new biological activity and cellular targets, 
suggesting that new protein functions might be uncovered from parasitoid venom studies.

\section{Leptopilina virus-like particles (VLPs) may provide insights into the transfer and targeting of venom proteins}

Some venom proteins interact with hosts through enzymatic or inhibitory activities or by functioning as ligands. Other venom proteins are targeted to specific host cells [31] and may induce uptake and/or signaling responses. The mode of action and entry of parasitoid venom proteins into host cells is largely unknown except in a few species whose venoms contain virus-like particles (VLPs) [33]. The best example of this are the VLPs of Leptopilina species, that are produced in the venom gland [34] and injected into host larvae [35] where they largely contribute to immunosuppression [36]. VLPs stored in the venom reservoir are ovoid to round shaped, singlemembrane vesicles, that range from 50 to $100 \mathrm{~nm}$ in size. They also contain a dense material punctuated by empty lacunae delimited by membranes with a similar appearance to late lysosomal vesicles and residual bodies that form in certain cells $[33,34]$. Proteomics identify no viral proteins and no nucleic acid is present in VLPs $\left[11^{\bullet}, 12^{\bullet}\right]$, which collectively suggests these vesicles are of cellular origin. Following injection into host larvae, VLPs target hemocytes, which results in morphological changes and/ or apoptosis [36]. These alterations may be due to delivery of venom proteins that are packaged in VLPs and released once VLPs enter hemocytes. This 'transport' could have been selected as a way for delivering a high level of toxins inside host cells while also protecting toxins from degradation inside the host. Interestingly, the number and shape of VLPs differs between Leptopilina species and strains [35,37], but whether this is related to differences in the nature and/or quantity of venom proteins, or to assembly mechanisms is unknown.

\section{Functional tools for venom study}

Transgenesis and targeted mutagenesis are usually not feasible approaches for genetically manipulating parasitoid wasps due to their small size and dependency on another organism (the host) for development. However, the function of venom proteins can be assessed by expressing recombinant proteins and conducting bioassay, or by knocking-down gene expression in wasps using RNA interference (RNAi). The first demonstrations of using RNAi to knock-down parasitoid gene expression were in the ectoparasitoid Nasonia vitripennis (Pteromalidae) [38-40] and two endoparasitoids in the genus Microplitis (Braconidae) [41,42]. We recently demonstrated that RNAi can also be used to knock-down genes expressed in the venom gland of L. boulardi [43]. RNAi screens thus have potential for studying the function of particular venom components by parasitizing hosts and studying associated phenotypic alterations.

\section{Future perspectives}

The restricted host ranges of most parasitoids together with tremendous variation in life history suggests that the diversity in composition and function of parasitoid venoms is likely high. These features also create a number of challenges for future studies. Key needs for the future include broader genomic or transcriptome data together with proteomic analysis of venoms from a greater diversity of parasitoids. Much more functional data is also needed, which requires development of assay methods for studying individual components and their activities in production of venom and/or their roles in altering the physiology of hosts. We fully anticipate that progress in these areas will lead to new adaptive concepts while also providing new pharmacological tools [44,45 $\left.{ }^{\bullet}\right]$.

\section{Acknowledgements}

We thank H. Mathé-Hubert and A. Iacovone for data production and for scientific discussions, Dr. Kimura for kindly providing a strain of Leptopilina japonica and a Japanese strain of L. heterotoma and M. Strand for helpful comments and editing of the manuscript. Funding was received from the French National Research Agency (ANR-09-BLAN-0243-1 and the 'Investments for the Future' LABEX SIGNALIFE ANR-11-LABX-002801), the INRA Department of Plant Health and Environment (SPE), the French PACA region (APEX Suzukill) and the European Union's Seventh Framework Programme for research, technological development and demonstration under grant agreement No. 613678 (DROPSA).

\section{References and recommended reading}

Papers of particular interest, published within the period of review, have been highlighted as:

\section{- of special interest}

•• of outstanding interest

1. Casewell NR, Wüster W, Vonk FJ, Harrison Ra, Fry BG: Complex - cocktails: the evolutionary novelty of venoms. Trends Ecol Evol 2013, 28:219-229 http://dx.doi.org/10.1016/j.tree.2012.10.020. A review on venomous life in the animal kingdom and the molecular evolution and functional convergence of venom proteins from different phyla. It provides recent advances and highlights the ecological and evolutionary novelty of venom systems and the use of toxins to find potential novel targets for pharmaceutical discovery.

2. Duda TF, Chang D, Lewis BD, Lee T: Geographic variation in venom allelic composition and diets of the widespread predatory marine gastropod Conus ebraeus. PLoS One 2009, 4:e6245 http://dx.doi.org/10.1371/journal.pone.0006245.t003.

3. Rodríguez de la Vega RC, Schwartz EF, Possani LD: Mining on scorpion venom biodiversity. Toxicon 2010, 56:1155-1161 http://dx.doi.org/10.1016/j.toxicon.2009.11.010.

4. Quicke DLJ: Parasitic wasps. London, UK: Chapman \& Hall; 1997,

5. Nappi A, Poirié M, Carton $Y$ : The role of melanization and cytotoxic by-products in the cellular immune response of Drosophila against parasitic wasps. Adv Parasitol 2009, 70: 99-121 http://dx.doi.org/10.1016/S0065-308X(09)70004-1.

6. Poirié M, Carton $Y$, Dubuffet A: Virulence strategies in parasitoid Hymenoptera as an example of adaptive diversity. $C R$ Biol 2009, 332:311-320 http://dx.doi.org/10.1016/j.crvi.2008.09.004.

7. Asgari S, Rivers DB: Venom proteins from endoparasitoid

- wasps and their role in host-parasite interactions. Annu Rev Entomol 2011, 56:313-335 http://dx.doi.org/10.1146/annurevento-120709-144849.

8. Colinet D, Mathé-Hubert H, Allemand R, Gatti J-L, Poirié M:

- Variability of venom components in immune suppressive parasitoid wasps: from a phylogenetic to a population approach. J Insect Physiol 2012, 59:205-212 http://dx.doi.org/ 
These two publications review the main proteins identified from the venom of parasitoid wasps and having known or putative biochemical functions.

9. Dorémus $\mathrm{T}$, Urbach $\mathrm{S}$, Jouan $\mathrm{V}$, Cousserans $\mathrm{F}$, Ravallec $\mathrm{M}$, Demettre E, Wajnberg E, Poulain J, Azéma-Dossat C, Darboux I et al.: Venom gland extract is not required for successful parasitism in the polydnavirus-associated endoparasitoid Hyposoter didymator (Hym. Ichneumonidae) despite the presence of numerous novel and conserved venom proteins. Insect Biochem Mol Biol 2013, 43:292-307 http://dx.doi.org/ 10.1016/j.jinsphys.2013.02.010.

10. Colinet D, Anselme C, Deleury E, Mancini D, Poulain J, AzemaDossat $\mathrm{C}$, Belghazi $\mathrm{M}$, Tarès $\mathrm{S}$, Pennacchio $\mathrm{F}$, Poirié $\mathrm{M}$ et al.: Identification of the main venom protein components of Aphidius envi, a parasitoid wasp of the aphid model Acyrthosiphon pisum. BMC Genomics 2014, 15:342 http:// dx.doi.org/10.1186/1471-2164-15-342.

11. Goecks J, Mortimer NT, Mobley JA, Bowersock GJ, Taylor J,

- Schlenke T: Integrative approach reveals composition of endoparasitoid wasp venoms. PLoS One 2013, 8:e64125 http:// dx.doi.org/10.1371/journal.pone.0064125.s007.

12. Colinet D, Deleury E, Anselme C, Cazes D, Poulain J, Azema-

- Dossat C, Belghazi M, Gatti J-L, Poirié M: Extensive inter- and intraspecific venom variation in closely related parasites targeting the same host: the case of Leptopilina parasitoids of Drosophila. Insect Biochem Mol Biol 2013, 43:601-611 http:// dx.doi.org/10.1016/j.ibmb.2013.03.010.

These two publications identify the main secreted proteins in the venom of Leptopilina heterotoma and $L$. boulardi based on combined transcriptomic and proteomic approaches. They show for the first time that close parasitoid species parasitizing the same host can have no major protein in common. The second publication also evidences a large difference in venom composition between two $L$. boulardi strains. Results suggest that venom can quickly evolve, possibly through rapid changes in regulation of gene expression.

13. Vincent B, Kaeslin M, Roth T, Heller M, Poulain J, Cousserans F, Schaller J, Poirié M, Lanzrein B, Drezen J-M et al.: The venom composition of the parasitic wasp Chelonus inanitus resolved by combined expressed sequence tags analysis and proteomic approach. BMC Genomics 2010, 11:693 http:// dx.doi.org/10.1186/1471-2164-11-693.

14. Zhu J-Y, Fang Q, Wang L, Hu C, Ye G-Y: Proteomic analysis of the venom from the endoparasitoid wasp Pteromalus puparum (Hymenoptera: Pteromalidae). Arch Insect Biochem Physiol 2010, 75:28-44 http://dx.doi.org/10.1002/arch.20380.

15. de Graaf DC, Aerts M, Brunain M, Desjardins CA, Jacobs FJ, Werren $\mathrm{JH}$, Devreese $\mathrm{B}$ : Insights into the venom composition of the ectoparasitoid wasp Nasonia vitripennis from bioinformatic and proteomic studies. Insect Mol Biol 2010 19:11-26 http://dx.doi.org/10.1111/j.1365-2583.2009.00914.x.

16. Burke GR, Strand MR: Systematic analysis of a wasp parasitism arsenal. Mol Ecol 2014, 23:890-901 http://dx.doi.org/10.1111/ mec.12648.

17. Mortimer NT, Goecks J, Kacsoh BZ, Mobley JA, Bowersock GJ: Parasitoid wasp venom SERCA regulates Drosophila calcium levels and inhibits cellular immunity. Proc Natl Acad Sci USA 2013, 110:9427-9432 http://dx.doi.org/10.1073/ pnas. 1222351110.

18. Van Vaerenbergh M, Debyser G, Devreese B, de Graaf DC

- Exploring the hidden honeybee (Apis mellifera) venom proteome by integrating a combinatorial peptide ligand library approach with FTMS. J Proteomics 2014, 99:169-178 http:// dx.doi.org/10.1016/j.jprot.2013.04.039.

An in-depth study of the honeybee venom proteome using a highly performant sample pretreatment and mass spectrometric technology. 102 proteins and peptides have been identified, 83 of them being described for the first time in a bee venom sample. Assignment of putative biological functions to all identified compounds largely expands the knowledge of bee venom toxicity and allergens.

19. Colinet D, Schmitz A, Cazes D, Gatti J-L, Poirié M: The origin of intraspecific variation of virulence in an eukaryotic immune suppressive parasite. PLoS Pathog 2010, 6:e1001206 http:// dx.doi.org/10.1371/journal.ppat.1001206.
20. Leluk J, Schmidt J, Jones D: Comparative studies on the protein composition of hymenopteran venom reservoirs. Toxicon 1989, 27:105-114 http://dx.doi.org/10.1016/ 0041-0101(89)90410-8.

21. Zhu JY, Fang Q, Wang L, Hu C, Ye GY: Proteomic analysis of the venom from the endoparasitoid wasp Pteromalus puparum (Hymenoptera: Pteromalidae). Arch Insect Biochem Physiol 2010, 75:28-44 http://dx.doi.org/10.1002/arch.20380.

22. Colinet D, Cazes D, Belghazi M, Gatti J-L, Poirié M: Extracellular superoxide dismutase in insects: characterization, function, and interspecific variation in parasitoid wasp venom. $J$ Biol Chem 2011, 286:40110-40121 http://dx.doi.org/10.1074/ jbc.M111.288845.

23. Asgari S, Zhang G, Zareie R, Schmidt O: A serine proteinase homolog venom protein from an endoparasitoid wasp inhibits melanization of the host hemolymph. Insect Biochem Mol Biol 2003, 33:1017-1024 http://dx.doi.org/10.1016/S09651748(03)00116-4.

24. Colinet D, Dubuffet A, Cazes D, Moreau S, Drezen JM, Poirié M: A serpin from the parasitoid wasp Leptopilina boulardi targets the Drosophila phenoloxidase cascade. Dev Comp Immunol 2009, 33:681-689 http://dx.doi.org/10.1016/j.dci.2008.11.013.

25. Vinchon S, Moreau SJM, Drezen JM, Prévost G, Cherqui A: Molecular and biochemical analysis of an aspartylglucosaminidase from the venom of the parasitoid wasp Asobara tabida (Hymenoptera: Braconidae). Insect Biochem Mol Biol 2010, 40:38-48 http://dx.doi.org/10.1016/ j.ibmb.2009.12.007.

26. Pieters R, Hunger SP, Boos J, Rizzari C, Silverman L, Baruchel A, Goekbuget N, Schrappe M, Pui C-H: L-asparaginase treatment in acute lymphoblastic leukemia: a focus on Erwinia asparaginase. Cancer 2011, 117:238-249 http://dx.doi.org/ $10.1002 /$ cncr. 25489.

27. Falabella $P$, Riviello $L$, Caccialupi $P$, Rossodivita $T$, Teresa Valente M, Luisa De Stradis M, Tranfaglia A, Varricchio $P$, Gigliotti S, Graziani $\mathrm{F}$ et al:: A gamma-glutamyl transpeptidase of Aphidius ervi venom induces apoptosis in the ovaries of host aphids. Insect Biochem Mol Biol 2007, 37:453-465 http:// dx.doi.org/10.1016/j.ibmb.2007.02.005.

28. Balakrishna S, Prabhune A: Gamma-glutamyl transferases: a structural, mechanistic and physiological perspective. Front Biol 2014, 9:51-65 http://dx.doi.org/10.1007/s11515-014-1288-0.

29. Wong ESW, Belov K: Venom evolution through gene duplications. Gene 2012, 496:1-7 http://dx.doi.org/10.1016/ j.gene.2012.01.009.

30. Fry BG, Roelants K, Champagne DE, Scheib H, Tyndall JD, King GF, Nevalainen TJ, Norman JA, Lewis RJ, Norton RS et al.: The toxicogenomic multiverse: convergent recruitment of proteins into animal venoms. Annu Rev Genomics Hum Genet 2009, 10:483-511 http://dx.doi.org/10.1146/ annurev.genom.9.081307.164356.

31. Colinet D, Schmitz A, Depoix D, Crochard D, Poirié M: Convergent use of RhoGAP toxins by eukaryotic parasites and bacterial pathogens. PLoS Pathog 2007, 3:e203 http://dx.doi.org/10.1371/ journal.ppat.0030203.

32. Byun-McKay SA, Geeta R: Protein subcellular relocalization: a new perspective on the origin of novel genes. Trends Ecol Evol 2007, 22:338-344 http://dx.doi.org/10.1016/j.tree.2007.05.002.

33. Gatti J-L, Schmitz A, Colinet D, Poirié M: Diversity of virus-like particles in parasitoids' venom: viral or cellular origin? In Parasitoid viruses: symbionts and pathogens. Edited by Beckage NE, Drezen J-M. Elsevier; 2009:181-192.

34. Morales J, Chiu H, Oo T, Plaza R, Hoskins S, Govind S: Biogenesis, structure, and immune-suppressive effects of virus-like particles of a Drosophila parasitoid, Leptopilina victoriae. J Insect Physiol 2005, 51:181-195 http://dx.doi.org/ 10.1016/j.jinsphys.2004.11.002.

35. Dupas S, Brehélin M, Frey F, Carton Y: Immune suppressive virus-like particles in a Drosophila parasitoid: significance of their intraspecific morphological variations. Parasitology 1996 113:207-212 http://dx.doi.org/10.1017/S0031182000081981. 
36. Rizki RM, Rizki TM: Parasitoid virus-like particles destroy Drosophila cellular immunity. Proc Natl Acad Sci U S A 1990, 87:8388-8392 http://dx.doi.org/10.1073/pnas.87.21.8388.

37. Gueguen G, Rajwani R, Paddibhatla I, Morales J, Govind S: VLPs of Leptopilina boulardi share biogenesis and overall stellate morphology with VLPs of the heterotoma clade. Virus Res. 2011, 160:159-165 http://dx.doi.org/10.1016/ j.virusres.2011.06.005.

38. Lynch JA, Desplan C: A method for parental RNA interference in the wasp Nasonia vitripennis. Nat Protoc 2006, 1:486-494 http:// dx.doi.org/10.1038/nprot.2006.70.

39. Olesnicky EC, Desplan C: Distinct mechanisms for mRNA localization during embryonic axis specification in the wasp Nasonia. Dev Biol 2007, 306:134-142 http://dx.doi.org/10.1016/ j.ydbio.2007.03.012.

40. Werren JH, Loehlin DW: Larval RNAi in Nasonia (parasitoid wasp). Cold Spring Harb Protoc 2009, 10:1-6 http://dx.doi.org/ 10.1101/pdb.prot5311.

41. Li K-M, Ren L-Y, Zhang Y-J, Wu K-M, Guo Y-Y: Knockdown of Microplitis mediator odorant receptor involved in the sensitive detection of two chemicals. J Chem Ecol 2012, 38:287-294 http://dx.doi.org/10.1007/s10886-012-0085-y.

42. Burke GR, Thomas Sa, Eum JH, Strand MR: Mutualistic polydnaviruses share essential replication gene functions with pathogenic ancestors. PLoS Pathog 2013, 9:e1003348 http://dx.doi.org/10.1371/journal.ppat.1003348.s004.

43. Colinet D, Kremmer L, Lemauf S, Rebuf C, Gatti JL, Poirié M: Development of RNAi in a Drosophila endoparasitoid wasp and demonstration of its efficiency in impairing venom protein production. J Insect Physiol 2014, 63:56-61 http://dx.doi.org/ 10.1016/j.jinsphys.2014.02.011.

44. Danneels E, Rivers D, de Graaf D: Venom proteins of the parasitoid wasp Nasonia vitripennis: recent discovery of an untapped pharmacopee. Toxins 2010, 2:494-516 http:// dx.doi.org/10.3390/toxins2040494.

45. Danneels E, Gerlo S, Heyninck K, Van Craenenbroeck K, De

- Bosscher K, Haegeman G, de Graaf DC: How the venom from the Ectoparasitoid Wasp Nasonia vitripennis exhibits anti- inflammatory properties on mammalian cell lines. PLOS One 2014, 9:e96825 http://dx.doi.org/10.1371/journal.pone.0096825. The authors demonstrate, using a well characterized NF-kB reporter gene assay, that $N$. vitripennis venom inhibits NF-kB activity in fibrosarcoma cells and the LPS-induced expression of NF-kB target Interleukin-6 (IL-6) in murine macrophage-like cells. This is the first report that venom from an ectoparasitic wasp is able to suppress NF-kB signaling and inflammatory responses in mammalian cell lines.

46. Price D, Bell H, Hinchliffe G, Fitches E, Weaver R, Gatehouse J: A venom metalloproteinase from the parasitic wasp Eulophus pennicornis is toxic towards its host, tomato moth (Lacanobia oleracae). Insect Mol Biol 2009, 18:195-202 http://dx.doi.org/ 10.1111/j.1365-2583.2009.00864.x.

47. Zhang G, Schmidt O, Asgari S: A calreticulin-like protein from endoparasitoid venom fluid is involved in host hemocyte inactivation. Dev Comp Immunol 2006, 30:756-764 http:// dx.doi.org/10.1016/j.dci.2005.11.001.

48. Parkinson N, Smith I, Audsley N, Edwards JP: Purification of pimplin, a paralytic heterodimeric polypeptide from venom of the parasitoid wasp Pimpla hypochondriaca, and cloning of the cDNA encoding one of the subunits. Insect Biochem Mol Biol 2002, 32:1769-1773 http://dx.doi.org/10.1016/S09651748(02)00135-2.

49. Asgari S, Zareie R, Zhang G, Schmidt O: Isolation and characterization of a novel venom protein from an endoparasitoid, Cotesia rubecula (Hym: Braconidae). Arch Insect Biochem Physiol 2003, 53:92-100 http://dx.doi.org/ 10.1002/arch.10088.

50. Richards EH, Dani MP: Biochemical isolation of an insect haemocyte anti-aggregation protein from the venom of the endoparasitic wasp Pimpla hypochondriaca and identification of its gene. J Insect Physiol 2008, 54:1041-1049 http://dx.doi.org/ 10.1016/j.jinsphys.2008.04.003.

51. Labrosse C, Stasiak K, Lesobre J, Grangeia A, Huguet E, Drezen JM, Poirié M: A RhoGAP protein as a main immune suppressive factor in the Leptopilina boulardi (Hymenoptera Figitidae)-Drosophila melanogaster interaction. Insect Biochem Mol Biol 2005, 35:93-103 http://dx.doi.org/10.1016/ j.ibmb.2004.10.004. 